\title{
South Africa gets out of hand
}

\section{The present sad condition of the Republic of South Africa is unlikely to last for very long. But the timescale of general impatience may be dangerously short.}

WHAT can be done and what should be said about the growing crisis in South Africa? Nature has no competence in the matter. which lies outside the terms of reference implicitly defined by a readership of professional scientists. Of course, there are some aspects of the condition of South Africa on which science has a bearing. There can be no genetic basis for the inequitable and offensive system of apartheid, which is not to say that apparent differences in the attainment of different races may not be induced by the systematic social deprivation of one (or several) of them. It is also pertinent, as in the argument begun just under a year ago by the thoughtless Southampton organizers of September's World Archaeological Congress, that academics outside South Africa cannot ostracize fellow-intellectuals working at South African institutions without irreparably and permanently damaging the cause of international scholarship. But there are also some commonsense considerations that deserve more attention than they are being given.

Those outside South Africa wishing to encourage change should prudently begin with an assessment of the time over which their hopes are likely to be realized. The temptation is to miscalculate that the system of apartheid is so near collapse that only modest pressure from outside will send it tumbling. This is why the cry for general economic sanctions is now widespread, not merely from outside South Africa, but by many of the black leaders within the republic. But that underestimates the capacity for survival of the Nationalist South African government. One of the most distasteful features of the apartheid system is that many of the black workers on whom the economy depends belong titularly not where they work but to artificial living places many miles away, to which they are supposed to return when they are out of work. If sanctions were effective enough to hurt the economy of South Africa, the republic government would be acting within its own laws if it chose to send the unemployed off to their "homelands" to starve in obscurity. The process would be difficult but not impossible, and would buy more time. Is it possible that well-wishers outside South Africa have allowed their distaste of the present system to lead them to too sanguine a view of the weakness of a government whose determination is, in other connections, its hallmark?

But if not sanctions, what? That is the general dilemma. The simplest answer is "selective sanctions", by which is meant a variety of schemes ranging from the cancellation of permission for South African aircraft to land elsewhere to a collective decision not to buy South African exports of certain kinds, fruit for example. But if full sanctions would not produce the intended effect, can half-sanctions succeed? (A few symbolic actions might nevertheless be worthwhile.) The difficulty running through these tortuous considerations is the frustration of governments elsewhere that they have no obvious means except the passive device of sanctions legally to influence internal affairs in South Africa.

Luckily, that does not imply that nothing can be done. Although the international banking system has been quietly helping to bring about the "disinvestment" in South Africa for which well-wishers have been asking, would it not now make sense, as a condition for the continued operation of South African companies as subsidiaries of companies registered elsewhere, that they should promptly follow employment practices of the kind that would be expected of them outside South Africa, treating people of different races on an equal footing and providing for the disadvantaged the kind of technical training that would allow them to function properly in their jobs? The cost could be high, but not necessarily greater than that of sanctions and certainly less than the cost of the international chaos that will supervene if South Africa falls apart. Indeed, it might even be worthwhile to encourage the South African subsidiaries of overseas corporations to break the apartheid laws. as Barclays Bank has just done by lending money to a black employee to buy a house in a district reserved for whites. When industrialized governments do not shrink from telling companies to instruct their overseas subsidiaries to which customers they may and may not sell high technology, why should they shrink from using this power constructively within South Africa?

\section{Trouble on the farm}

The problems now facing farmers will not go away overnight.

Most developed countries have long since been forced by economic reality to reduce the scale on which they maintain oncetraditional industries such as shipbuilding and steel manufacture. In many places, farming will be the next in line. So much has been clear for several years, some would say decades. Much of the food that farmers in developed countries now grow with the crucial help of government subsidies could already be grown more cheaply elsewhere, in Australia. New Zealand, Argentina and Zimbabwe, for example. As time passes. the list of potential suppliers of temperate foodstuffs will be or could be increased by the addition of many now-developing countries, which would conform well with Adam Smith's principle that the economic use of resources requires a division of labour: in the modern world. some must grow food and others make computers.

That is what the textbooks say. The reality is very different. The subsidies industrialized governments pay their farmers. which have ensured over the years that the industrialized world is awash with food that impoverished nations cannot afford to buy, serve a multitude of functions, not all of them respectable. Occasionally, the old strategic argument still surfaces that a country less than self-sufficient in food production is vulnerable to starvation in time of war, but this can hardly carry weight when most governments fear that future wars will be over before most people know they have begun, and when government warehouses are in any case filled to the brim with food that nobody wants. The social argument, that the farming community is the repository of an invaluable tradition whose erosion would spell the loss of crucial elements in the constitution of advanced societies, contrasts oddly with the continual war between farmers and many of the societies in which they are embedded over environmental issues. for example. (Too often. 